\title{
Ulnar artery aneurysm and hypothenar hammer syndrome
}

\author{
Yogesh Kumar, Kusum Hooda, Lawrence Lo, Ian Karol
}

Department of Radiology, Yale New Haven Health System at Bridgeport Hospital, Bridgeport, Connecticut, USA

\section{Correspondence to} Dr Yogesh Kumar, yogesh.kumar@bpthosp.org

Accepted 3 November 2015

\section{DESCRIPTION}

A right-hand dominant patient presented with pain and a tender mass in the hypothenar eminence, and with paraesthesia of the fourth and fifth fingers. The patient was referred for MRI of the hand, which showed thrombosed ulnar artery aneurysm and an irregularity of the superficial ulnar artery, suggesting a diagnosis of hypothenar hammer syndrome (HHS) (figures 1 and 2).

HHS results from repetitive microtrauma to the ulnar artery at the level of Guyon's canal, as it passes over the hamate bone. This may result in arterial wall damage, thus leading to vessel irregularity, aneurysm formation or thrombosis. Aneurysm can cause compression of the sensory branch of the ulnar nerve. ${ }^{1}$

HHS is usually found in men of working age with occupations that involve repetitive blunt trauma to the hands, this has also been observed in athletes with sports-related injuries. Patients may present with a tender mass in the hypothenar eminence, pain in the palm, numbness in the fourth and fifth fingers, and ischaemia of the fourth and fifth fingers.

Although the diagnosis can be confirmed easily with sonography, by showing ulnar artery thrombosis or aneurysm, MRI and MR angiography (MRA) provide a comprehensive evaluation of the hypothenar region. MRI can be used to evaluate osteochondral, neural, vascular, tendinous and ligamentous structures. MRA can be useful in detecting early changes of arterial wall thickening, irregularity and aneurysms. MRA is also useful in

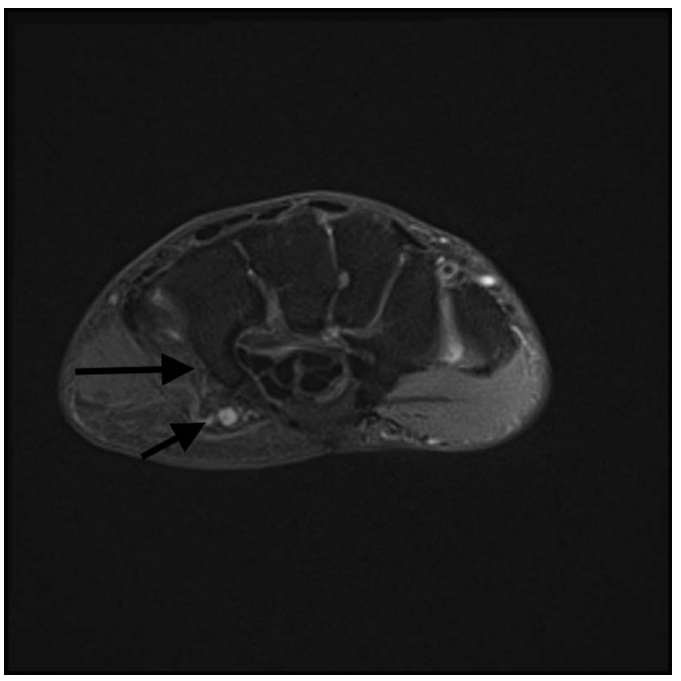

Figure 1 Axial short tau inversion recovery image at the level of the hook of hamate (larger arrow) showing ulnar artery aneurysm (smaller arrow).

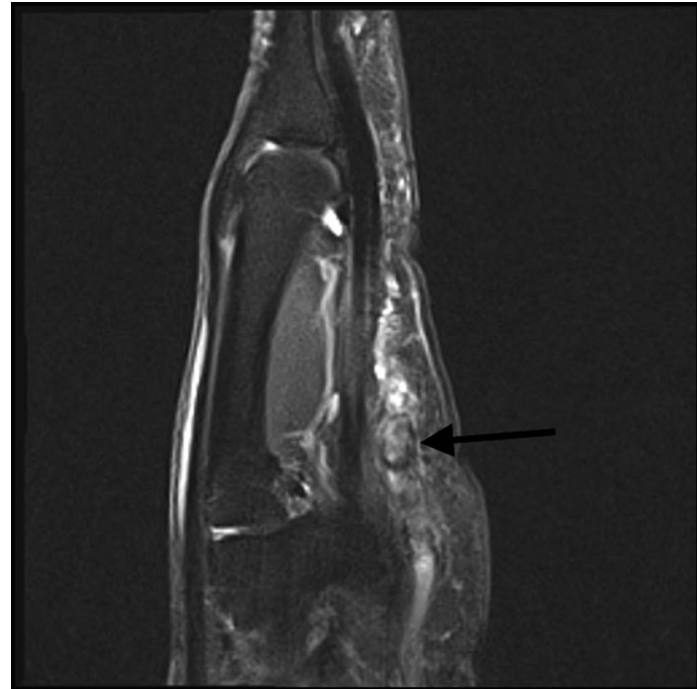

Figure 2 Sagittal short tau inversion recovery image showing ulnar artery aneurysm (arrows).

demonstrating the site of segmental occlusion of the ulnar artery. ${ }^{2}$

Patients with HHS are advised rest from the offending activity, smoking cessation and therapy with vasodilators such as calcium channel blockers. The thrombosed segments are usually treated with surgical excision and reconstruction with a vein graft.

The differential diagnosis for HHS includes benign tumours of the hand including lipomas, schwannomas, vascular malformations and ganglion cysts, which can mimic ulnar artery aneurysms. Thromboangiitis Obliterans (Buerger's disease) can present as an irregularity; it has a corkscrew appearance on MRA of the hand, and can mimic HHS. However, involvement of digital arteries in the former while involvement around the

\section{Learning points}

- Hypothenar hammer syndrome (HHS) is caused by damage to the ulnar artery either by occupational or sporting activities.

- The diagnosis should be suspected when a younger male presents with symptoms of pain, palpable lump and ischaemia, in the dominant hand.

- MRI and MR angiography can be very helpful in diagnosing HHS by showing arterial abnormalities including a pathognomonic 'corkscrew' appearance, aneurysm and thrombosis. 


\section{Images in...}

wrist joint in HHS will help in differentiating these two entities. Thus, in appropriate clinical settings, MR and MRA can conclusively diagnose HHS by depicting aneurysm formation and the pathognomonic 'corkscrew' appearance. ${ }^{3}$

Contributors YK prepared the manuscript. KH helped in figure legends. $L L$ and IK provided expert musculoskeletal MRI guidance for the manuscript preparation.

Competing interests None declared.

Patient consent Not obtained.
Provenance and peer review Not commissioned; externally peer reviewed.

\section{REFERENCES}

1 Cooke RA. Hypothenar hammer syndrome: a discrete syndrome to be distinguished from hand-arm vibration syndrome. Occup Med 2003;53:320-4.

2 Ablett CT, Hackett LA. Hypothenar hammer syndrome: case reports and brief review. Clin Med Res 2008;6:3-8.

3 Blum AG, Zabel JP, Kohlmann R, et al. Pathologic conditions of the hypothenar eminence: evaluation with multidetector CT and MR imaging. Radiographics 2006:26:1021-44.

Copyright 2015 BMJ Publishing Group. All rights reserved. For permission to reuse any of this content visit http://group.bmj.com/group/rights-licensing/permissions.

BMJ Case Report Fellows may re-use this article for personal use and teaching without any further permission.

Become a Fellow of BMJ Case Reports today and you can:

- Submit as many cases as you like

- Enjoy fast sympathetic peer review and rapid publication of accepted articles

- Access all the published articles

- Re-use any of the published material for personal use and teaching without further permission

For information on Institutional Fellowships contact consortiasales@bmjgroup.com

Visit casereports.bmj.com for more articles like this and to become a Fellow 